training; what is more, they are not properly appreciated. Not one man in a thousand knows the amount of harm that is done to young children by placing them under the tuition of testy, irritable, explosive, and neurotic teachers.

B. A. Hinsdale.

Cleveland, O., Oct. 3 .

\section{Objects in Teaching.}

THE value of objects in giving correct ideas was brought forcibly to my mind not long since while teaching a class in natural philosophy at the New York State Institution for the Blind, Batavia, N.Y.

It was my custom to place before them, the day before its uses and the principles which it illustrated were to be discussed, a given piece of apparatus, that, by becoming familiar with the form and construction, its application might the more readily be appreciated. One of the class, a young man blind from infancy, with a fondness for machinery of all kinds and a quick perception of the use of such as was placed before him, would frequently study the lesson in advance, picturing to himself as carefully as possible the apparatus described. These pictures, as he told me afterwards, were far from correct.

The thorough examination and understanding of each succeeding object, of whatever kind, add so much to the stock of correct concepts, which is valuable not only for itself, but for its aid by comparison in understanding others.

One of our most successful teachers described to her class, ranging in age from eight to twelve, as vividly as she could without naming it, a ladder. Among other things, she stated that it was made of wood, had parallel sides, etc., using such terms as would seem to be most readily understood, and then asked for the name of the thing described. For some time no one could tell : various things were mentioned, one boy suggesting 'map,' the maps for the blind being cut in relief from wood, with the sides of the frame parallel.

A little girl had for the first time a bird, a stuffed specimen, placed in her hands, and was much surprised to find that it had but two legs, having supposed until then that birds had four.

Whatever may be said for or against object-teaching for seeing children, that of blind children is successful proportionately as it is objective.

J. T. MOREY.

Perkins Institution, South Boston, Mass., Oct. 3 .

\section{Color-Blindness.}

IN the opening article in Science last week (Sept. 30) an idea was suggested, or recalled, that may be of value; and I offer it in view of the possible value. I have observed for twenty years or more a difference in the power of my two eyes, at times, to discriminate in light reds when viewed at a distance of fifty feet or more; and I think this difference in the visual power of the two organs depends very largely, if not altogether, on the way in which the eyes are used. If I have been occupied with work that called one eye into active exercise, where the mind was occupied in discussing the surface or object viewed, particularly if the light was variable, then I find persons appear different, according to which eye is used. Not only so, but the two eyes do not focus the same; the image, with the tired eye, being farther off than that from the eye that is rested, and of a dull gray color. If I go to a lecture under such circumstances, there appear to be two lecturers, - one pale and shadowy behind; and above, the other, which seems, perhaps by contrast, to take on a brighter hue. Under such circumstances, I close the tired eye, - as I have come to consider it, - and give it a rest, or go out into the fields and give it a feast on green. Now, may not the eyes of engineers vary as to visual power in the discrimination of colors with excessive use? If both eyes are exhausted and need rest, the individual would not be able to detect his own disability. Now, if that is so, it is of importance to the public that no one should be on duty for a great length of time, where the safety of any depend on the discriminating power of the eyes as to colors.

And would it not be well, in testing eyes, to note the condition of the individual, - whether fresh or tired, just from work or just from rest?

Geo. F. Waters.

Boston, Oct. 3.

\section{Percentage of Ash in Human Bones of Different Ages.}

REFERRING to Watt's 'Dictionary of Chemistry,' under the article 'Bone,' we find two tables of analyses of bones, - - one by Von Bibra, and the other by Frémy. These two scientists do not arrive at the same conclusion. Von Bibra states that "the portion of inorganic matter in bone is smaller in youth than in age, although no regular gradation can be observed;" while Frémy holds that "the bone of a fotus was found to yield the same quantity of ash as that of a woman of ninety-seven years of age." Although the actual number of analyses made by these investigators was large, yet simple inspection of their tables will show that very few were made of the same bone in each case; and it is evident that a comparison between a femur on the one hand, and a tibia on the other, could not be trustworthy.

It occurred to me as worth while to supplement their lists; and I here present what may be considered a report of progress in that direction, very much yet remaining to be done.

The extreme difficulty of getting supplied with material the history of which is both certain and satisfactory renders the work exceedingly slow.

The bone for examination was in every instance cut from the dense portion of the shaft of the femur. No subject was taken who had, so far as known, suffered from rickets or other serious bone-disease, and women of recent confinement were also excluded. All specimens were obtained either from living persons (amputations) or those recently dead. After crushing in a steel mortar, extracting with ether, and again crushing, the ash was determined by incineration in a platinum dish. The results are in the appended table.

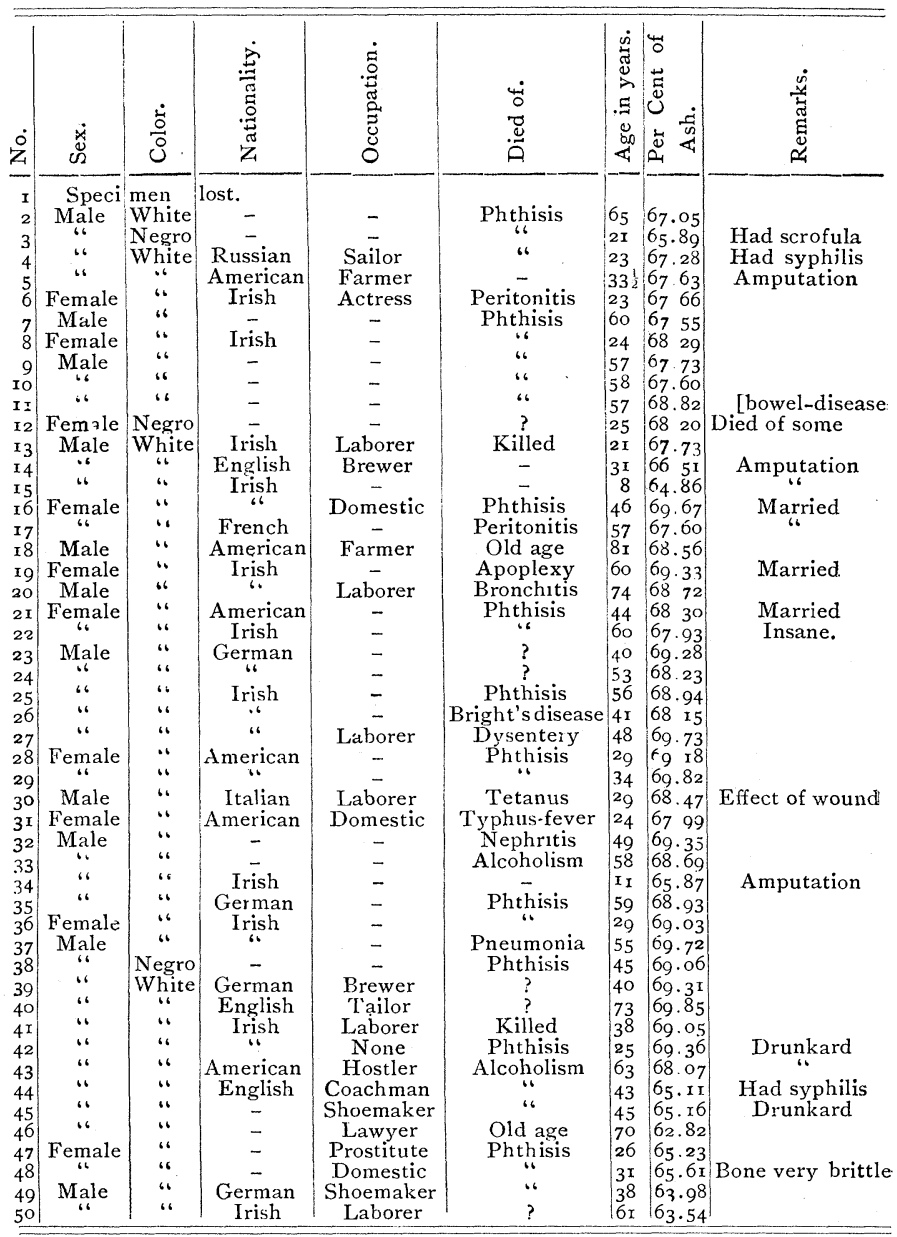

I think enough has been done to show that the common belief in the increased brittleness of bone with advancing years being due to increased percentage of inorganic salts, is without foundation. The appended table indicates that after manhood is reached, no variation in quantity of ash takes place as the years roll on.

"The greater brittleness of the bones in age is attributed by 